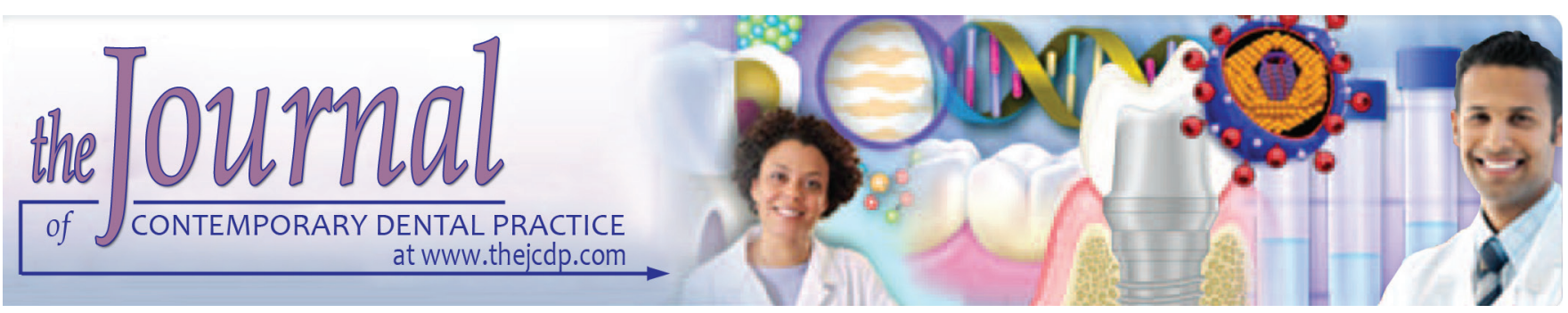

\title{
Comparative Evaluation of the Strength of Denture Base Resin repaired with Glass Fiber-reinforced Acrylic Resin: An in vitro Study
}

\author{
${ }^{1}$ Ramacham P Shanoj, ${ }^{2} \mathrm{P}$ Abdul Razak, ${ }^{3} \mathrm{~K}$ Nanda Kumar, ${ }^{4}$ John Francis, ${ }^{5}$ Kavya Ashok \\ ${ }^{6}$ Kattakath KMM Sameer
}

\begin{abstract}
Aim: The present study aimed at evaluating and comparing the transverse strength of heat polymerizing acrylic resin samples repaired using glass fiber-reinforced autopolymerizing acrylic resin with varying gap widths at the fracture site.
\end{abstract}

Materials and methods: Heat polymerizing acrylic resin samples of dimensions $65 \times 10 \times 2.5 \mathrm{~mm}$ each were fabricated. Ten of these were used as control. In the rest of samples, two grooves were fabricated and surface treated with ethyl acetate. The repair gap width was standardized at 4, 3, 2, and $1 \mathrm{~mm}$. Totally, 80 samples were equally divided into these four groups. Glass fiber-reinforced autopolymerizing acrylic resin was used to repair these samples. The repaired samples and the control groups were subjected to three-point bending test, and the findings were analyzed statistically.

Results: It was observed that with increase in gap width, their transverse strength decreased. Most of the fractures occurred at the joint interface of parent and repair material. The fracture within the repaired material occurred highest in the group that had $4 \mathrm{~mm}$ gap, followed by groups that had 3 and $2 \mathrm{~mm}$ gaps. In the group with $1 \mathrm{~mm}$ gap, there was no occurrence of fracture within the repaired material.

Conclusion: To achieve optimum repair strength of a repaired denture, the gap width should not be greater than $1 \mathrm{~mm}$.

Clinical significance: The study will aid in determining the ideal gap width for denture repair to prevent fracture and also the clinical application of glass fiber-reinforced autopolymerizing acrylic resin.

\footnotetext{
${ }^{1-5}$ Department of Prosthodontics, MES Dental College Malappuram, Kerala, India

${ }^{6}$ Department of Periodontics, MES Dental College, Malappuram Kerala, India

Corresponding Author: Ramacham P Shanoj, Department of Prosthodontics, MES Dental College, Malappuram, Kerala, India e-mail: shanojrp_27@yahoo.co.in
}

Keywords: Acrylic resin, Denture base, Glass fiber reinforcement, Repair, Varying gap width.

How to cite this article: Shanoj RP, Razak PA, Kumar KN, Francis J, Ashok K, Sameer KKMM. Comparative Evaluation of the Strength of Denture Base Resin repaired with Glass Fiber-reinforced Acrylic Resin: An in vitro Study. J Contemp Dent Pract 2018;19(7):792-798.

Source of support: Nil

Conflict of interest: None

\section{INTRODUCTION}

The loss of teeth by accident or disease has plagued mankind throughout the ages. Dentures aid in restoring function and appearance, by adapting to the contemporary materials that were available at that period of history. This included denture bases carved out of hardwood, ivory, or bone, with natural teeth held by screws or by other means. ${ }^{1-3}$ Dr Walter Wright was responsible for the introduction of polymethyl methacrylate (PMMA) denture base resin in 1937, which continues to be the material of choice for denture fabrication. ${ }^{4}$ This is because of its distinctive properties like dimensional stability, ease of processing, low water sorption, accuracy of fit, improved esthetics, and freedom from toxicity. However, poor resistance to force of impaction, bending, and fatigue ${ }^{5}$ make them susceptible to fracture. This may occur as a result of poor fit, accidental dropping, or lack of balanced occlusion, resulting in need for fabrication of a new denture, ${ }^{6-8}$ which is time consuming. Hence, repairing the denture base as a temporary or a definitive measure for esthetic and functional needs of the patient needs is preferable. ${ }^{9}$

When the denture repair is carried out, the original shape and strength of the denture should be maintained. Also, the repairing process should be easy, inexpensive, and 
has to be carried out in minimum time with proper match of the color of the denture base material. ${ }^{9,10}$ Furthermore, there should be a proper adhesion between the denture base and repair material. This adhesion is improved by surface treating the broken edges of the denture base with certain chemicals before packing the repair material. ${ }^{11-15}$

Using autopolymerizing (self-cure) acrylic resin for repair is simple, easy, and quick. However, the material has insufficient transverse strength and can result in refracture at the repaired site. This requires incorporation of various reinforcement materials, glass fibers being one among them. ${ }^{16-19}$ Glass fibers are advantageous because of their specific strength and high specific modulus, which receive stress without deformation. They also provide better esthetics, as they do not alter color. ${ }^{17}$

One of the important steps in the repair procedure involves trimming the borders of the fractured sites of the denture, thereby, creating a gap between the fractured parts, which will subsequently be packed with the repair material. The width of the gap between the segments to be repaired determines the amount of repair material that needs to be packed, thereby, affecting the strength of the repaired denture, although the amount of gap width to be created is debatable. ${ }^{20}$

The fracture resistance of the denture base, repaired with a combination of surface treatment with ethyl acetate and a reinforcing material, like glass fiber, with varying gap widths has not been extensively studied. Therefore, the current study was aimed at evaluating and comparing the transverse strengths of denture bases repaired with glass fiber-reinforced autopolymerizing acrylic resin with varying gap widths and determining the optimum amount of gap width to be created between the fractured sites.

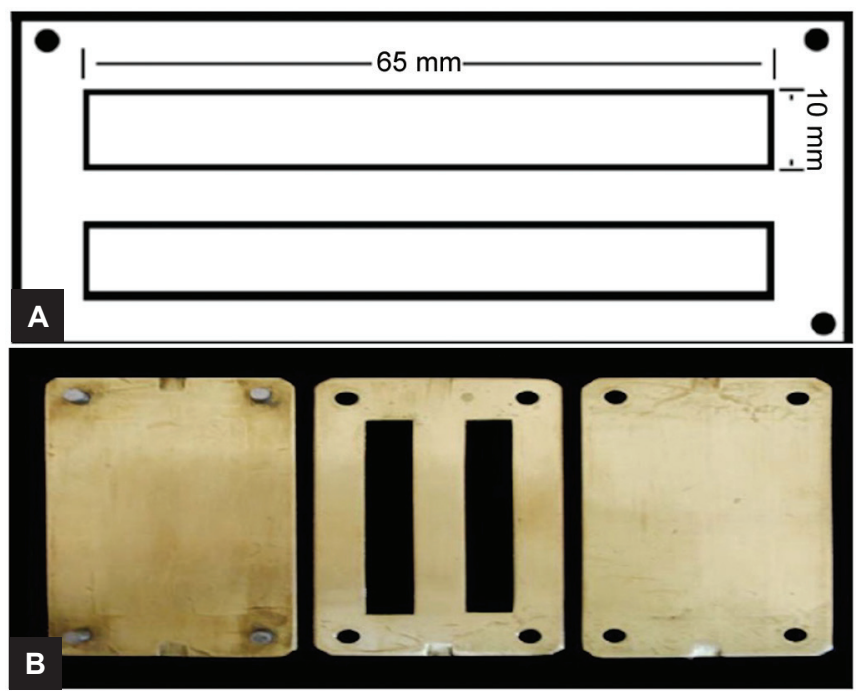

Figs $1 \mathrm{~A}$ and $\mathrm{B}$ : Schematic representation of customized threepiece brass flask for fabrication of unfractured heat-polymerizing acrylic resin samples and repair of the heat-polymerizing acrylic resin strips (flask $\mathrm{A}$ )

\section{MATERIALS AND METHODS}

In this in vitro study, the specimens were fabricated in two customized flasks-flask A and flask B.

Flask A: It was a customized three-piece brass flask, of dimensions $90 \times 50 \times 10 \mathrm{~mm}$. It contained two mold spaces corresponding to the dimensions of unfractured heatpolymerizing acrylic resin samples $(65 \times 10 \times 2.5 \mathrm{~mm})$. Four screws were present at the corners of the flask, which helped in assembling the three pieces. This customized flask helped in the fabrication of two unfractured heatpolymerizing acrylic resin samples and two repaired samples of heat-polymerizing acrylic resin strips at one time (Fig. 1).

Flask B: This was a customized three-piece brass flask, of dimensions $90 \times 65 \times 10 \mathrm{~mm}$, containing eight mold spaces, two each arranged in four rows on the flask. The mold spaces in the first, second, third, and fourth rows were used for fabricating butt-shaped edge profile of heat-polymerizing acrylic resin strips. The dimensions of mold spaces were $30.5 \times 10 \times 2.5 \mathrm{~mm}$ (first row), $31 \times 10$ $\times 2.5 \mathrm{~mm}$ (second row), $31.5 \times 10 \times 2.5 \mathrm{~mm}$ (third row), and $32 \times 10 \times 2.5 \mathrm{~mm}$ (fourth row). Each strip had two rectangular grooves on one side, of dimensions $5 \mathrm{~mm}$ long and $2 \mathrm{~mm}$ wide (Fig. 2).

Fabrication of acrylic strips: Briefly, a thin coat of petroleum jelly (MediSoft; Medi Smith Pharma Lab, Lot No 003) was applied on the inner surface of the flask A. This was to aid in easy removal of the heat-polymerizing acrylic resin. Following this, the powder (polymer) and liquid (monomer) of the heat-cured acrylic resin (DPI Heat Cure ${ }^{\mathrm{TM}}$; Dental Products of India Ltd., Batch No. 192) was mixed in the ratio $3: 1$ by volume. The material was kneaded thoroughly in dough stage and was packed into the mold spaces in the flasks (Figs 3A aand B). Intermittent pressure was applied using bench press to
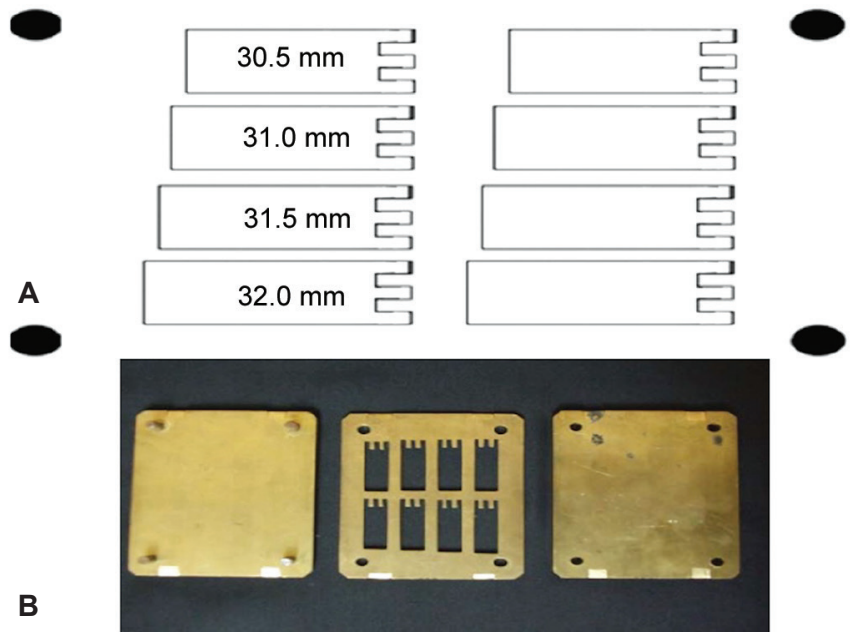

Figs 2A and B: Schematic representation of customized threepiece brass flask for the fabrication of heat-polymerizing acrylic resin strips (flask B) 


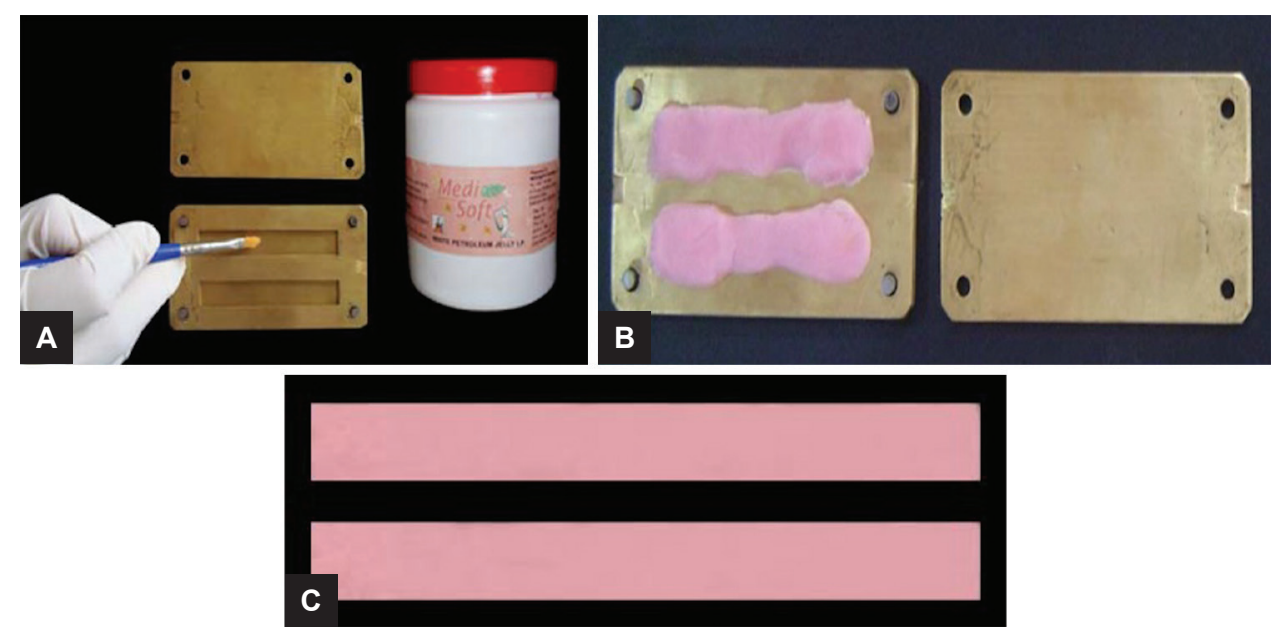

Figs $3 A$ to $C$ : (A) Inner surface of the flask was coated with a thin layer of petroleum jelly. (B) The material was packed in dough stage into the mold spaces in Flask A. (C) Finished and polished heat-polymerized acrylic resin samples

close this flask. Following flash removal, the flask was transferred to a clamp and bench, cured for 30 minutes, and then immersed in the water bath in an acrylizer, and curing was done at $74^{\circ} \mathrm{C}$ for 2 hours followed by $100^{\circ} \mathrm{C}$ for 1 hour. After curing, the flask was bench cooled slowly to room temperature and samples were retrieved, finished, and polished (Fig. 3C). These samples were stored in distilled water. Ten strips were fabricated and assigned as control group.

\section{Fabrication of Experimental Heat-polymerizing Acrylic Resin Strips}

A total of 80 butt-shaped edge profile heat-polymerizing acrylic resin strips were made in flask $\mathrm{B}$. The procedure followed for the fabrication of these strips was similar to the procedure carried out for the fabrication of unfractured heat-polymerizing acrylic resin samples using flask A. Totally, 20 each of dimensions $30.5 \times 10 \times 2.5 \mathrm{~mm}$ (group I), $31 \times 10 \times 2.5 \mathrm{~mm}$ (group II), $31.5 \times 10 \times 2.5 \mathrm{~mm}$ (group III), and $32 \times 10 \times 2.5 \mathrm{~mm}$ (group IV) were fabricated. Each strip had two rectangular grooves on one side of dimensions $5 \mathrm{~mm}$ long and $2 \mathrm{~mm}$ wide (Fig. 4). The grooved end of each strip was considered as repair site, which were sandblasted with 250- $\mu \mathrm{m}$ sized alumina particles for 10 seconds. Following this, they were cleaned in an ultrasonic bath for 4 minutes to remove any traces of alumina particles and stored in distilled water. Surface treatment of heat-polymerizing acrylic resin strips was done with ethyl acetate (Mercktm India Ltd, Batch No. S15S550624). Each sample group was swabbed with ethyl acetate for a period of 60 seconds, using a camel hair brush after which they were washed with water and dried. For the repair process, the ethyl acetate surface-treated heat-polymerizing acrylic resin strips were placed at the two ends of the mold with the repair sites facing each other. A gap of $4 \mathrm{~mm}$ remained

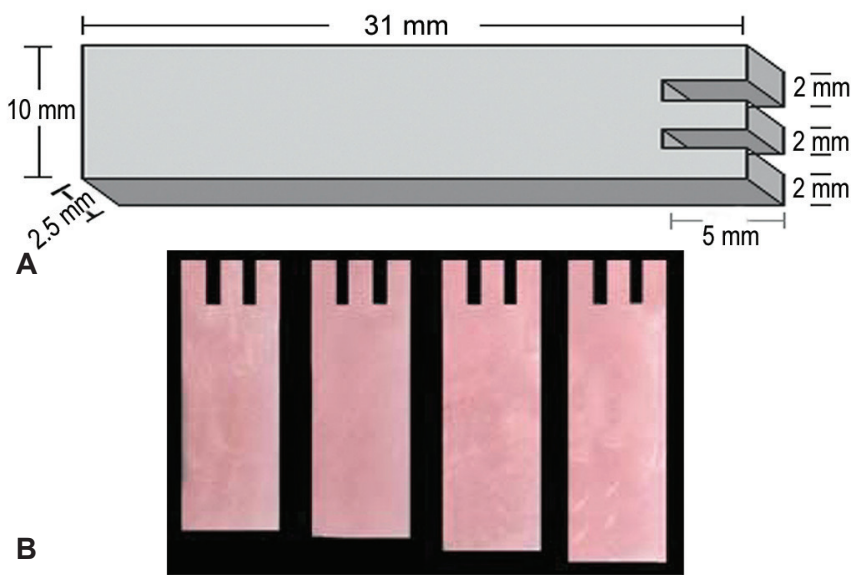

Figs 4A and B: Each strip with two rectangular grooves on one side, $5 \mathrm{~mm}$ long and $2 \mathrm{~mm}$ wide

constant for all group I samples. In a similar manner for repairing group II, III, and IV samples, a gap width of 3, 2 , and $1 \mathrm{~mm}$ respectively, was maintained (Fig. 5). They were repaired using autopolymerizing acrylic resin (DPIRRCold Cure, Batch No. 117) reinforced with glass fibers (Advantex ${ }^{\mathrm{TM}}$ Owens Corning ${ }^{\circledR}$ Company, USA, Lot No. 06148T304) (diameter $16.8 \mu \mathrm{m}$ ). The concentration of the glass fibers used was $1 \%$ by volume of the polymer. Glass fibers were cut into $2 \mathrm{~mm}$ (approx) segments and thoroughly mixed in the predetermined quantity with monomer (liquid) and the polymer (powder) in 1:3 ratio by volume. When the dough stage was reached, the material was packed into the space present between two heat-polymerizing acrylic resin strips (Fig. 6A). After trial closure and flash removal, final closure was carried out in a bench press for two hours. This ensured complete polymerization. A240-grit silicon carbide paper was used for finishing the strips. They were then stored in distilled water for 48 hours. This procedure was repeated to 

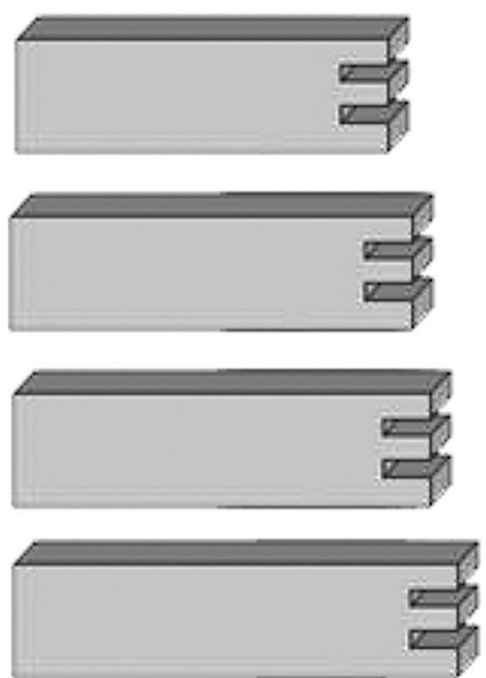

Fig. 5: Schematic representation of heat-polymerizing acrylic resin strips with repair sites facing each other with gap width of $4,3,2$, and $1 \mathrm{~mm}$ for groups I, II, III, and IV respectively
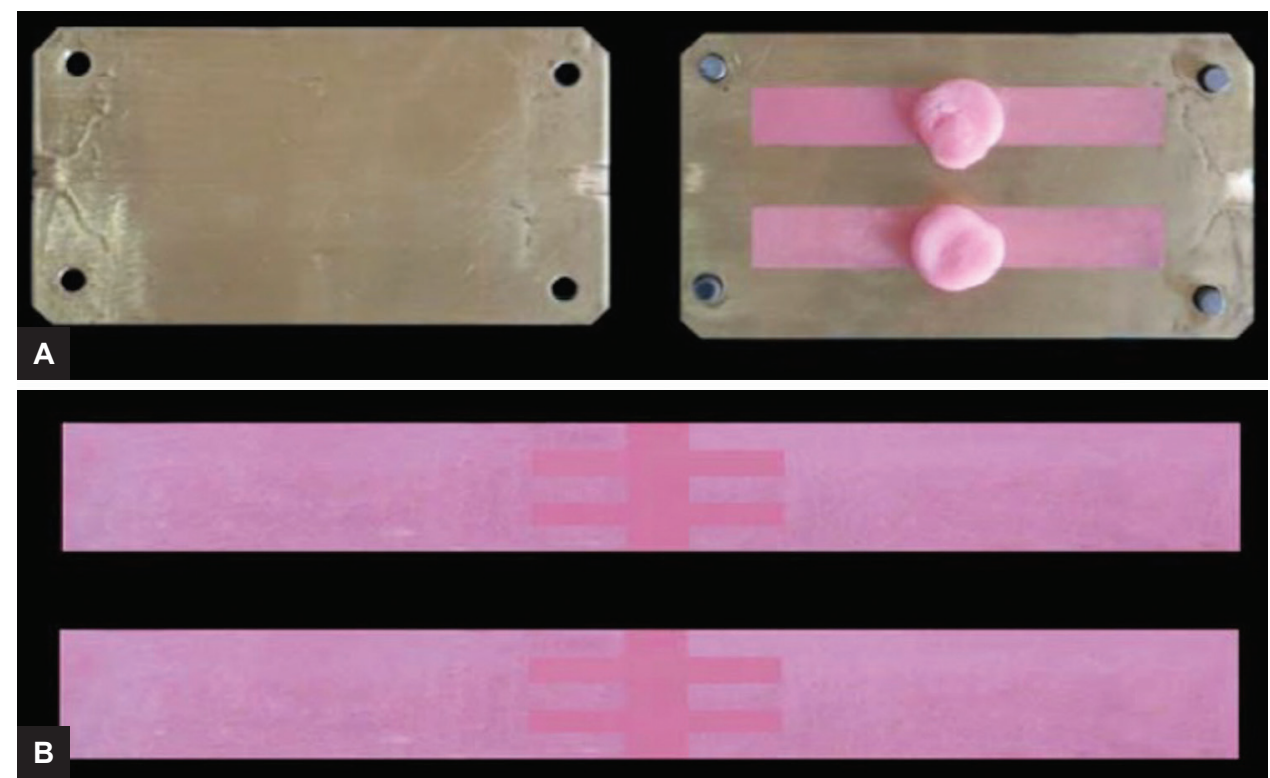

Figs $6 A$ and $B:(A)$ Material packed into the space between two heat-polymerizing acrylic resin strips. (B) Samples repaired using glass fiber-reinforced autopolymerizing acrylic resin fabricate repaired heat-polymerizing acrylic resin samples of all groups. For easy referral, these samples repaired using glass fiber-reinforced autopolymerizing acrylic resin with gap width of $4 \mathrm{~mm}$ was assigned as group I, $3 \mathrm{~mm}$ as group II, $2 \mathrm{~mm}$, and $1 \mathrm{~mm}$ as group III and group IV respectively (Fig. 6B). Three-point bending test was used for testing the transverse strength of the repaired samples using Instron testing machine (Model 4206, Instron Corp, Canton, MA). The cross-head speed of the machine was set at $2 \mathrm{~mm}$ per minute at a distance of $50 \mathrm{~mm}$. The load was applied at the center of the repaired area, and the loading was continued until fracture occurred. The breaking load was noted.

The site of fracture in repaired samples was evaluated to determine whether the fracture site was within the repair material or at the interface between parent and repair material.

The breaking load values were obtained in kilograms. The transverse repair strength values were obtained using formula $\mathrm{S}$ (transverse strength) $=3 \mathrm{PL} / 2 \mathrm{bd}^{2}$, where $\mathrm{P}$ is the load at fracture, $L$ is the length, $b$ is width, and $d$ is the thickness of the specimen. The transverse strength values obtained in $\mathrm{kg} / \mathrm{mm}^{2}$ were converted into MPa by multiplying with 9.8. The values were then tabulated and mean and standard deviation were obtained. One way analysis of variance (ANOVA) was used for comparing the mean values of the control and the four test groups. Tukey's honest significant difference was used for intercomparison between each group. The p-value $<0.05$ ) was considered as significant. Statistical tests were carried out 
Table 1: The transverse strength of all the unfractured heatpolymerizing acrylic resin samples (control group)

\begin{tabular}{ll}
\hline Specimen no. (Control) & Transverse strength (MPa) \\
\hline 1 & 155.702 \\
2 & 165.463 \\
3 & 158.407 \\
4 & 160.053 \\
5 & 156.408 \\
6 & 154.761 \\
7 & 160.759 \\
8 & 156.408 \\
9 & 159.348 \\
10 & 164.640 \\
Mean & 159.19490 \\
Standard deviation & 3.653896 \\
\hline
\end{tabular}

using software package Statistical Package for the Social Sciences version 7.0 .

\section{RESULTS}

For the control group, the transverse strength was found to be highest at $159.19 \pm 3.65 \mathrm{MPa}$ (mean \pm standard deviation) (Table 1). The transverse strength in $\mathrm{MPa}$ (mean \pm standard deviation) of the groups I, II, III and IV was $110.54 \pm 3.65,115.67 \pm 3.61,118.56 \pm 3.50$, and $120.47 \pm 3.62$ (Table 2). The values were $69.44,72.65,74.47$, and $75.67 \%$ of the control group respectively. The fracture within the repaired material occurred the highest in group I, followed by groups II and III. In group IV samples, there was no occurrence of fracture within the repaired material. The descriptive statistics, ANOVA, and multiple comparisons of the groups are in Tables 3 and 4 respectively.

Table 3: Transverse strength ANOVA

\begin{tabular}{lll}
\hline & $f$-value & Significance $(p)$ \\
\hline Between groups & 294.749 & 0.0005
\end{tabular}

Table 4: Multiple comparisons dependent variable: Transverse strength (MPa)

\begin{tabular}{llll}
\hline Group $(x)$ & Group $(y)$ & $\begin{array}{l}\text { Mean difference } \\
(x-y)\end{array}$ & $p$-value \\
\hline Group I & Group II & 5.1157 & 0.021 \\
& Group III & -8.0087 & 0.001 \\
& Group IV & -9.9138 & 0.001 \\
& Control & -48.6396 & 0.0005 \\
Group II & Group III & -2.8930 & 0.388 \\
& Group IV & -4.7981 & 0.035 \\
& Control & -43.5239 & 0.0005 \\
Group III & Group IV & -1.9051 & 0.760 \\
& Control & -40.6309 & 0.0005 \\
Group IV & Control & -38.7258 & 0.0005 \\
\hline
\end{tabular}

Table 2: The transverse strength of samples

\begin{tabular}{lllll}
\hline \multirow{2}{*}{$\begin{array}{l}\text { Specimen } \\
\text { no. }\end{array}$} & \multicolumn{4}{c}{ Transverse strength (MPa) } \\
\cline { 2 - 5 } & Group I & Group II & Group III & Group IV \\
\hline 1 & 109.132 & 114.777 & 117.247 & 119.011 \\
2 & 114.189 & 119.716 & 122.068 & 124.185 \\
3 & 116.306 & 121.010 & 124.303 & 126.302 \\
4 & 105.016 & 110.426 & 113.131 & 115.248 \\
5 & 107.839 & 112.425 & 115.483 & 117.129 \\
6 & 111.132 & 116.424 & 119.246 & 121.128 \\
7 & 113.131 & 118.070 & 121.363 & 123.362 \\
8 & 106.075 & 111.367 & 114.072 & 116.188 \\
9 & 112.425 & 117.012 & 120.304 & 121.951 \\
10 & 110.30 & 115.483 & 118.423 & 120.187 \\
Mean & 110.55530 & 118.56400 & 115.67100 & 120.46910 \\
Standard & 3.604921 & 3.612997 & 3.502269 & 3.617539 \\
deviation & & & & \\
\hline
\end{tabular}

\section{DISCUSSION}

The PMMA resin is extensively used as the material of choice for the fabrication of removable complete and partial dentures. ${ }^{4}$ Studies have shown that more than $60 \%$ of the dentures fabricated with PMMA fractured within the first three years of its fabrication, where midline fracture comprised $29 \%$ of the total repairs made. Of these, $71 \%$ were seen in maxillary and $29 \%$ were seen in mandibular complete dentures. ${ }^{8}$

Among the various repair materials available, conventional methods of denture base repair involves the use of autopolymerizing or heat-polymerizing acrylic resins. ${ }^{10}$ Despite the heat-polymerizing acrylic resin demonstrating superior strength, the increased amount of time needed and the requirement of custom-split cast gypsum mold limit its use as a repair material. ${ }^{9}$

While using autopolymerizing acrylic resin, though a convenient and most popular repair material as it allows for simple and quick repair, the insufficient transverse strength of this resin can cause refracture at the repaired site. The transverse strength can be enhanced by surface treatments ${ }^{11-15}$ and the incorporation of various reinforcement materials. ${ }^{16-19}$

One of the important steps in the repair procedure involves trimming the borders of the fractured denture and creating a gap. The width of the gap determines the amount of repair material that needs to be packed, thereby, affecting the strength of the repaired denture. Acrylic resins reinforced with glass fibers have shown maximum fracture resistance as compared with aramid fibers ${ }^{17,18}$ and carbon fibers. ${ }^{19}$ Also, glass fibers do not alter the color of repaired resin. ${ }^{17}$ Therefore, in the present study, glass fibers were used as a reinforcement material. A study by Stipho ${ }^{10}$ compared the effect of varying the concentration of glass fiber in the repair strength 
and concluded that the strength was highest when the concentration of glass fiber was $1 \%$ of the volume of the polymer. In accordance with the results of this study, 1\% concentration of glass fiber was used in the present study for reinforcement. Surface treatment of the fractured site before repairing has been proven to increase its fracture resistance. ${ }^{11-13}$ Earlier studies have found that certain surface treatment agents (chloroform, acetone) have carcinogenic potentials and are difficult to handle. ${ }^{11-15}$ In this study, ethyl acetate was used as a surface treatment agent since it is used as a flavoring agent in pharmaceutical preparations and in artificial fruit essences, and is found to be absolutely safe. ${ }^{20}$ In the present study, it was found that, as the gap width between the repaired specimens increased from 1 to $4 \mathrm{~mm}$, their transverse strength decreased, which is in accordance with the study by Stipho and Stipho, ${ }^{6}$ who in their study stated that gap width contributes to the distribution of stresses in the repaired specimens. According to various studies, the gap between the segments to be repaired ranged from 1.5 to $3 \mathrm{~mm} \cdot{ }^{6,11,13}$ The reason for the increased transverse strength as the gap width decreased could be due to decrease in the volume of the repair material that is incorporated in between the gap, which, in turn, reduced the degree of shrinkage of the repair material. The decrease in gap width also resulted in better esthetics as it reduces the color difference between the repair material and denture base. Beyli and von Fraunhofer, ${ }^{20}$ in their study, to determine the transverse strength, fracture strength, and deflection of PMMA denture base resin using unreinforced repaired acrylic resin specimens at varying gap widths of 1 to $5 \mathrm{~mm}$, found that there was no significant difference in transverse strengths with variation in the gap width. This is contradictory to the results obtained in the present study, wherein the increased gap width caused decrease in transverse strength of the repaired specimens. The difference in the results could be due to the fact that the specimens used in the study by Beyli and von Fraunhofer ${ }^{20}$ were not surface treated with ethyl acetate and reinforced with glass fibers. Also, the dimensions of the samples used in this study by Beyli and von Fraunhofer ${ }^{20}(40 \times 7 \times 2.5 \mathrm{~mm})$ were different from that of the present study $(65 \times 10 \times 2.5 \mathrm{~mm})$, wherein a butt-shaped edge profile with two grooves was used on the repair site compared with the former, wherein a butt-shaped edge profile with no grooves was used. Another important aspect evidenced by this study was the site of occurrence of fracture in the repaired samples. In groups I, II, III, and IV, most of the fractures occurred at the parent and repair material interface. This result was in accordance with the results of an earlier study by Beyli and von Fraunhofer, ${ }^{20}$ who in their study, found that all fractures occurred at the heat-cured denture base material and repair resin interface, which could be due to the fact that sharp-angled surfaces of the butt-shaped edge profile increases the stress concentration, causing an adhesive failure and thus resulting in fracture. The fracture within the repaired material occurred the highest in group I, which could be due to the increased bulk of the repair material as the gap width between the repaired specimens increased.

However, there are certain limitations in this in vitro study. It was not possible to duplicate the different types of stresses that are generated in the oral cavity. Also, the curvature of the denture follows the contours of the anatomic tissues and could not be simulated in this study as rectangular acrylic strips were used. In clinical practice, the fracture of the dentures does not usually occur in a linear pattern, but mostly in various irregular configurations, which is not included in the study. Finally, certain factors like the homogeneity of mix, presence of internal porosity, and the release of stresses during finishing and polishing procedures cannot be always controlled in spite of following standard protocols.

\section{CONCLUSION}

Within the limits of the present study and based on the results obtained, it may be concluded that gap width not greater than $1 \mathrm{~mm}$ provide optimum repair strength of a repaired denture, and better bonding between the parent and repair material is required by the incorporation of better joint configurations and surface treatments that can reduce stress concentrations and increase the bond strength.

\section{REFERENCES}

1. Peyton FA. History of resins in dentistry. Dent Clin North Am 1975 Apr;19(2):211-222.

2. Rueggeberg FA. From vulcanite to vinyl, a history of resins in restorative dentistry. J Prosthet Dent 2002 Apr;87(4): 364-379.

3. Machado C, Sanchez E, Azer SS, Uribe JM. Comparative study of the transverse strength of three denture base materials. J Dent 2007 Dec;35(12):930-933.

4. Eick JD. Biologic properties of denture base resins. Dent Clin North Am 1977 Apr;21(2):459-464.

5. Kelly E. Fatigue failure in denture base polymers. J Prosthet Dent 1969 Mar;21(3):257-266.

6. Stipho HD, Stipho AS. Effectiveness and durability of repaired acrylic resin joints. J Prosthet Dent 1987 Aug;58(2): 249-253.

7. Smith DC. Recent developments and prospects in dental polymers. J Prosthet Dent 1962 Nov-Dec;12(6):1066-1078.

8. Hargreaves AS. The prevalence of fractured dentures. A survey. Br Dent J 1969 May;126(10):451-455.

9. Ng ET, Tan LH, Chew BS, Thean HP. Shear bond strength of microwaveable acrylic resin for denture repair. J Oral Rehabil 2004 Aug;31(8):798-802. 
10. Stipho HD. Repair of acrylic resin denture base reinforced with glass fiber. J Prosthet Dent 1998 Nov;80(5):546-550.

11. Shen C, Colaizzi FA, Birns B. Strength of denture repairs as influenced by surface treatment. J Prosthet Dent 1984 Dec;52(6):844-848.

12. Nagai E, Otani K, Satoh Y, Suzuki S. Repair of denture base resin using woven metal and glass fiber: effect of methylene chloride surface pretreatment. J Prosthet Dent 2001 May;85(5):496-500.

13. Arima T, Nikawa H, Hamada T. Composition and effect of denture base resin surface primers for reline acrylic resins. J Prosthet Dent 1996 Apr;75(4):457-462.

14. George R, D'Souza M. Surface chemical treatment with ethyl acetate and repair of fractured denture base resins: an in-vitro analysis of transverse strengths. J Indian Prosthodont Soc 2001;1:41-44.

15. Sarac YS, Sarac D, Kulunk T, Kulunk S. The effect of chemical surface treatments of different denture base resins on the shear bond strength of denture repair. J Prosthet Dent 2005 Sep;94(3):259-266.

16. Gutteridge DL. The effect of including ultra high modulus polyethylene fiber on impact strength of acrylic resin. Br Dent J 1986 Mar;164(6):177-180.

17. John J, Gangadhar SA, Shah I. Flexural strength of heatpolymerized poly(methyl methacrylate) denture resin reinforced with glass, aramid, or nylon fibers. J Prosthet Dent 2001 Oct;86(4):424-427.

18. Kanie T, Fuji K, Arikawa H, Inoue K. Flexural properties and impact strength of denture base polymers reinforced with woven glass fibers. Dent Mater 2000 Mar;16(2):150-158.

19. De Boer J, Vermilyea SG, Brady RE. The effect of carbon fiber orientation on the fatigue resistance and bending properties of two denture resins. J Prosthet Dent 1984 Jan;51(1): 119-121.

20. Beyli MS, von Fraunhofer JA. Repair of fractured acrylic resin. J Prosthet Dent 1980 Nov;44(5):497-503. 